\title{
Chemical enhancers of posttranscriptional gene silencing in Arabidopsis
}

\author{
FLORENCE JAY, ${ }^{1}$ MAXIME VITEL, ${ }^{2}$ FLORIAN BRIOUDES, ${ }^{1}$ MÉLISSA LOUIS, ${ }^{2}$ THOMAS KNOBLOCH, ${ }^{2}$ \\ and OLIVIER VOINNET ${ }^{1}$ \\ ${ }^{1}$ Department of Biology, Swiss Federal Institute of Technology (ETH Zürich), 8092 Zürich, Switzerland \\ ${ }^{2}$ Bayer S.A.S., Biochemistry and New Technology, 69263 Lyon Cedex 09, France
}

\begin{abstract}
RNAi mediated by small-interfering RNAs (siRNAs) operates via transcriptional (TGS) and posttranscriptional gene silencing (PTGS). In Arabidopsis thaliana, TGS relies on DICER-LIKE-3 (DCL3)-dependent 24-nt siRNAs loaded into AGO4-clade ARGONAUTE effector proteins. PTGS operates via DCL4-dependent 21-nt siRNAs loaded into AGO1-clade proteins. We set up and validated a medium-throughput, semi-automatized procedure enabling chemical screening, in a 96-well in vitro format, of Arabidopsis transgenic seedlings expressing an inverted-repeat construct from the phloem companion cells. The ensuing quantitative PTGS phenotype was exploited to identify molecules, which, upon topical application, either inhibit or enhance siRNA biogenesis/activities. The vast majority of identified modifiers were enhancers, among which Sortin1, Isoxazolone, and [5-(3,4-dichlorophenyl)furan-2-yl]-piperidine-1-ylmethanethione (DFPM) provided the most robust and consistent results, including upon their application onto soil-grown plants in which their effect was nonautonomous and long lasting. The three molecules increased the RNAi potency of the inverted-repeat construct, in large part by enhancing 21-nt siRNA accumulation and loading into AGO1, and concomitantly reducing AGO4 and DCL3 levels in planta. A similar, albeit not identical effect, was observed on 22-nt siRNAs produced from a naturally occurring inverted-repeat locus, demonstrating that the molecules also enhance endogenous PTGS. In standardized assays conducted in seedling extracts, the three enhancers selectively increased DCL4-mediated processing of in vitro-synthesized double-stranded RNAs, indicating the targeting of a hitherto unknown PTGS component probably independent of the DCL4-cofactor DOUBLE-STRANDED RNA-BINDING 4 (DRB4). This study establishes the proof-of-concept that RNAi efficacy can be modulated by chemicals in a whole organism. Their potential applications and the associated future research are discussed.
\end{abstract}

Keywords: Arabidopsis; chemical screen; enhancers-suppressors; in vitro assay; RNAi; siRNA

\section{INTRODUCTION}

In plants, endogenous RNA interference (RNAi) is triggered by the conversion of various sources of long double-stranded (ds)RNAs into populations of small-interfering RNAs (siRNAs). dsRNAs may be spawned by read-through transcription at sense-antisense loci, by the action of RNAdependent RNA polymerases (RDRs), or by transcribed loci arranged into inverted-repeats (IRs). At the core of siRNA biogenesis is a class of RNase III enzymes called Dicerlike (DCL) proteins, of which there are four representatives (DCL1-4) in the model plant species Arabidopsis thaliana. siRNAs are then incorporated into multiprotein effector complexes known as RNA-induced silencing complexes (RISCs) that invariably contain one representative of the conserved ARGONAUTE (AGO) protein family, of which

Corresponding author: voinneto@ethz.ch

Article is online at http://www.rnajournal.org/cgi/doi/10.1261/rna. 068627.118 . there are 10 paralogs in Arabidopsis (AGO1-10). As part of RISCs, small RNAs (sRNAs) guide AGOs to sequencecomplementary DNA or RNA, which they silence via transcriptional (TGS) or posttranscriptional gene silencing (PTGS), respectively (Bologna and Voinnet 2014).

RNAi operated through TGS depends on DCL3-dependent 24-nt siRNAs loaded into AGO4-clade AGOs. The 24-nt siRNAs are mostly spawned by repeats and transposable elements, replete in plant genomes, and mediate RNA-directed DNA methylation (RdDM) primarily at their loci-of-origin, often resulting in TGS when promoter regions are targeted (Cuerda-Gil and Slotkin 2016). Thus, by dampening transcription of TEs, RdDM and TGS contribute to

(C) 2019 Jay et al. This article is distributed exclusively by the RNA Society for the first 12 months after the full-issue publication date (see http://rnajournal.cshlp.org/site/misc/terms.xhtml). After 12 months, it is available under a Creative Commons License (Attribution-NonCommercial 4.0 International), as described at http://creativecommons.org/licenses/by-nc/4.0/. 
the maintenance of genome integrity. RNAi operated via PTGS, on the other hand, functions mainly via DICERLIKE-4 (DCL4)-dependent 21-nt siRNAs, which, loaded into AGO1-clade proteins, mediate endonucleolytic cleavage or "slicing" of target mRNAs. Twenty-one-nucleotide endo-siRNAs are generated from RDR6-dependent long dsRNA or processed directly from the products of IR loci including prototypical MIRNA genes (Bologna and Voinnet 2014). Endogenous PTGS plays developmental roles, notably by enabling patterning of leaf polarity and juvenile-toadult phase transition in Arabidopsis and other species via RDR6-dependent, so-called trans-acting (tasi)RNAs (Gasciolli et al. 2005; Poethig et al. 2006). Like other endogenous siRNAs, 21-nt tasiRNAs have non-cell-autonomous effects, yielding PTGS phenotypes that generate activity gradients from their sites of biogenesis, potentially enabling a morphogenetic output (Chitwood et al. 2009; Schwab et al. 2009). Other tasiRNA-like molecules serve to regulate large gene families including NBS-LRRs that confer immunity to plants against a variety of pathogens (Shivaprasad et al. 2012; Boccara et al. 2014). DCL4 and its surrogate, DCL2, play direct antiviral roles by processing dsRNA features of replicating viral genomes into virus-derived siRNAs (vsiRNAs), which, loaded into mainly AGO1 and AGO2, target viral RNA for destruction (Szittya and Burgyán 2013).

A large class of endogenous DCL1-dependent products called microRNAs (miRNAs) derive as single species, as opposed to populations, from imperfect stem-loop precursor transcripts encoded in the genome by dedicated MIRNA genes. miRNA biogenesis is a stepwise, DCL1-dependent nuclear process whereby primary miRNA transcripts (primiRNAs) are first converted into miRNA stem-loop precursors (pre-miRNAs) from which the mature miRNA is excised, loaded, and exported to the cytosol as a miRNAAGO complex in a CRM1-dependent manner (Bologna et al. 2018). The DCL1 pri-to-pre-miRNA converting activity is also probably required to excise the double- from singlestranded parts of $I R$ transcripts generating the siRNA populations evoked above. Like most PTGS-related siRNAs, miRNAs are loaded nearly exclusively into AGO1-clade AGOs to regulate the steady-state levels (via slicing) and/ or rates of translation of target mRNAs displaying perfect or near-perfect sequence complementarity. Also like all plant siRNAs, miRNAs are protected at their $3^{\prime}$ ends by 2'-O-methylation mediated by the RNA methyl-transferase HUA ENHANCER 1 (HEN1), the lack of which results in $3^{\prime}$ end poly-uridylation and subsequent exonucleolytic degradation of si/miRNA strands (reviewed in Bologna and Voinnet 2014).

Forward and reverse genetics has identified a plethora of DCL1 cofactors required for its nuclear stepwise activities, uncovering highly sophisticated regulatory mechanisms. In contrast, cofactors of the siRNA-producing DCL2, $D C L 3$, and DCL4 remain essentially unknown with the ex- ception of double-stranded RNA binding (DRB) proteins that interact with and assist some of these enzymes by anchoring their long dsRNA substrates. These DRBs were identified by reverse genetics due to their similarities with DRB1, also known as HYPONASTIC LEAVES 1 (HYL), a key interactor of DCL1 in miRNA biogenesis (Vazquez et al. 2004; Hiraguri et al. 2005; Adenot et al. 2006). In particular, DRB4 physically interacts with DCL4 to facilitate processing of long dsRNA (Adenot et al. 2006), an assisting role negatively regulated by the related DRB4-interacting proteins DRB7.1 and DRB7.2 (Tschopp et al. 2017). DRBs aside, regulatory mechanisms for DCL2, DCL3, and DCL4 activities, should they exist, remain mysterious, raising the issue of their potential genetic redundancy. Indeed, all siRNA-generating DCLs in Arabidopsis share a continuum of hierarchical activities on the same long dsRNA substrates (Deleris et al. 2006). There is also the unexplored possibility that some DCL cofactors may have other RNA silencing-unrelated functions essential for fertility or embryonic growth. Also, null mutations in AGO1, the shared effector of endogenous siRNA-, antiviral- and miRNA-mediated PTGS, cause compromised growth and sterility (Bohmert et al. 1998).

We reasoned that, perhaps, factors facilitating or modulating siRNA biogenesis/activities in Arabidopsis might be amenable to chemical compound screens overcoming their potential genetic redundancy, embryonic lethality, and/or sterility. Forward chemical compound screens are commonly used in unicellular organisms and cell cultures. Owing to its small size and well-controlled growth, Arabidopsis, as a whole organism, is also amenable to these approaches under appropriate automation and imaging conditions. Chemical screens in Arabidopsis have, for instance, enabled studies of hormone signaling, biotic/abiotic stress or gravity sensing (Hicks and Robert 2014). To screen for RNA silencing activities entails, of course, accessible readouts of the underlying molecular mechanisms, which are commonly provided by transgenic activity sensors. While sensor-based chemical screens have revealed likely genetically inaccessible facets of TGS in Arabidopsis (Zhang et al. 2012; Dinh et al. 2014), chemical modifiers of PTGS are yet to be documented in any plant species. Identifying PTGS-modifying compounds would not only provide enabling tools to explore the underlying mechanisms, but also, potentially, to modulate traits endowed by experimental RNAi or endo-siRNA-mediated regulations, as well as antiviral defense.

\section{RESULTS AND DISCUSSION}

\section{An in vitro chemical screen to identify both inhibitors and enhancers of the Arabidopsis PTGS pathway}

To evaluate the feasibility of a screen for chemical modifiers of the PTGS pathway, we used the Arabidopsis SUC-SUL reporter line, in which the phloem companion-cell specific 
AtSUC2 promoter drives expression of an IR transgene, the key genetic features of which are summarized below. SUC-SUL silences non-cell-autonomously the endogenous and ubiquitously expressed SULFUR (SUL) mRNA, which is involved in chlorophyll biosynthesis. In leaves, this causes a vasculature-centered bleached phenotype (Fig. 1A), which, under controlled in vitro growth conditions manifests itself most robustly at the seedling stage (Leaf 1-to7). Of the 21-nt (DCL4-dependent) and 24-nt (DCL3-dependent) siRNA species produced from the SUC-SUL locus, the former is necessary and sufficient to silence
A

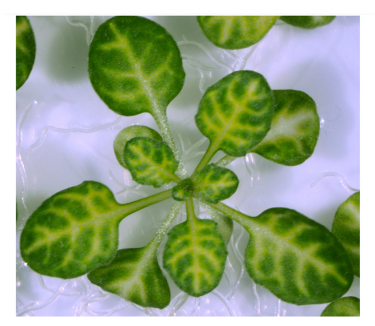

B
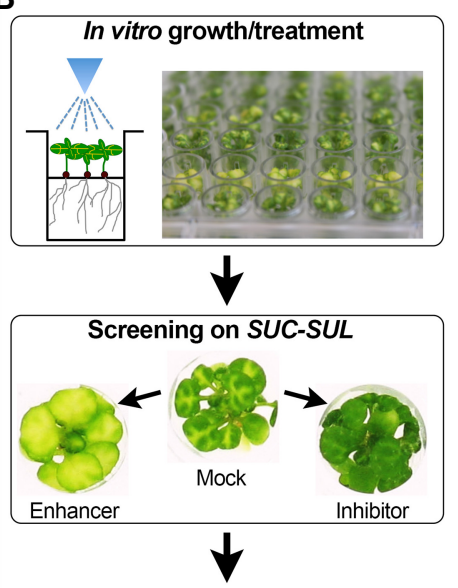

False positive removal AtSUC2-GFP

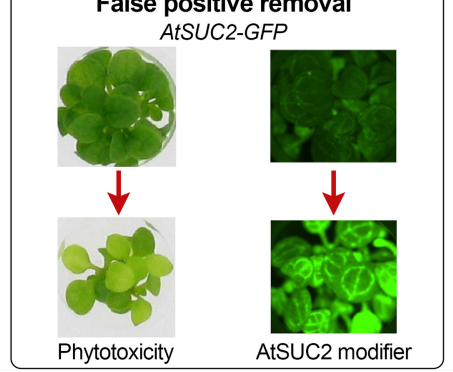

C

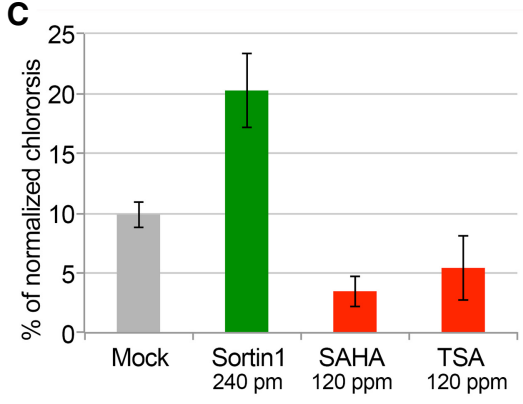

D

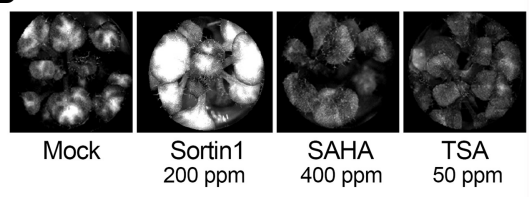

E

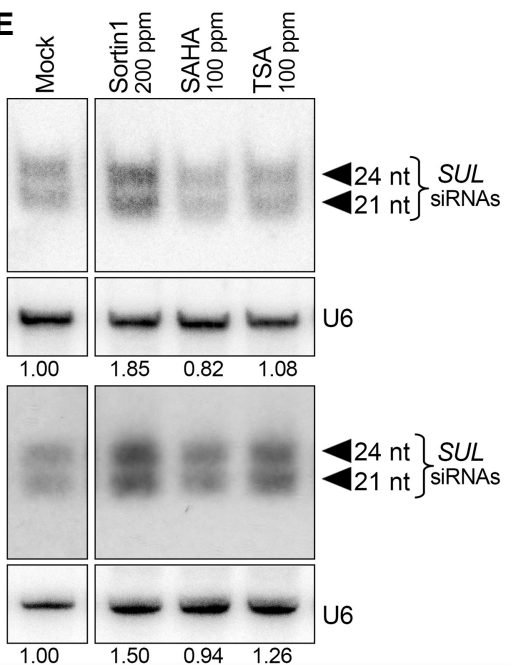

FIGURE 1. Screening and validation of chemical molecules affecting the PTS pathway. (A) Phenotype of a SUC-SUL plantlet grown in vitro. (B) Experimental layout to screen and select in vitro chemical molecules that inhibit or enhance the Arabidopsis PTGS pathway. (C) Percentage of the chlorotic phenotype of SUC-SUL seedlings treated with Sortin1, SAHA, or TSA, normalized to the mock treatment. Error bars, mean $\pm 95 \%$ confidence intervals; $N=8$. (D) Chlorotic phenotypes of the SUC-SUL seedlings treated with mock, Sortin1, SAHA, or TSA. (E) Northern blot analysis of the SUL siRNAs in SUC-SUL seedlings treated with mock, Sortin1, SAHA, or TSA, as obtained in two independent experiments. (Upper panels) Experiment \#1; (bottom panels) experiment \#2. (U6) Control for equal RNA loading. Relative quantification of the SUL siRNA signals normalized to U6 are indicated below the panels, with 1.00 arbitrary set for mock treatments.
SUL via PTGS in an AGO1-dependent manner (Dunoyer et al. 2005; Brodersen et al. 2008). Additionally, SUCSUL long dsRNAs over-accumulate in the hypomorphic dcl1-9 mutant background when the activities of DCL2, DCL3, and DCL4 are simultaneously abrogated, whereas DCL1 sole contribution to SUL siRNA production is modest ma converting activity is required upstream of and to facilitate dsRNA excision from the sin(Dunoyer SUL primary transcript (Dunoyer et al. 2007). Finally, and counterintuitively given its DCL4-assisting role, bleaching in the SUCSUL system remains unaffected in the loss-of-function drb4-1 background. The 21-nt siRNA levels are reduced in drb4-1 yet those of the 24-nt siRNAs are concomitantly strongly increased due, presumably, to DRB3, which assists DCL3, accessing more SUC-SUL dsRNA substrates. The excess in 24nt siRNAs is such that some of these species anomalously mediate PTGS by loading into AGO1 instead of cognate AGO4-clade AGOs (Dunoyer et al. 2007; Haas et al. 2008).

Forward EMS screens conducted previously on SUC-SUL have identified genetic modifiers indicating that variations in 21-nt SUL siRNA production/movement readily translate into reduced/increased chlorosis (Dunoyer et al. 2005). Thus, SUC-SUL could enable isolation of both PTGS-enhancers and PTGS-suppressors via chemical screening. To test this idea, 7-d-old SUC-SUL seedlings were grown in vitro into 96-well plates (four-five seedlings per well) under conditions of synchronous development. To ensure high reproducibility, automated liquid-handling robotics was used to spray the 96-well plates with tested chemical compounds (Fig. 1B). Seven days later, each well was inspected digitally under the stereo-microscope for subsequent software-based quantification of chlorosis. The bleached surface was integrated and compared to that of mock-treated seedlings used as a reference, resulting in a percentage of normalized chlorosis. A standard analysis typically involved $N=12$ well 
replicates in 96-well plates. Candidate molecules were classified as putative enhancers or putative inhibitors if they respectively increased or reduced the chlorotic surface of SUC-SUL seedlings (Fig. 1B).

We anticipated two major sources of false-positives that would possibly confound the screen's readout. The first one would result from molecules that enhance or reduce the activity of the companion cell-specific AtSUC2 promoter driving the SUC-SUL IR construct. These would alter dsRNA production and, consequently, siRNA processing, causing modified bleaching phenotypes not reflecting modified RNAi per se. The second nonmutually exclusive limitation was that of mere phytotoxicity of the molecules, usually manifested as extended chlorotic patches. To circumvent both of these potential caveats, the tested molecules were systematically sprayed, in parallel, onto seedlings of AtSUC2-GFP plants (Imlau et al. 1999) without the SUC-SUL background and further inspected under normal light (phytotoxicity) and epifluorescence (modified AtSUC2-GFP activity) (Fig. 1B).

\section{In vitro validation of the experimental layout using a set of "educated guess" molecules}

The practicability/robustness of the above setting was first tested with an 80-molecules panel chosen via educated guess based on our genetic understanding of SUL silencing and of PTGS in general. For instance, several EMS-induced mutations inhibiting SUL silencing affect genes involved in RdDM and heterochromatin formation, which are also required in related settings of non-cell-autonomous RNAi and suggest the contribution of as yet poorly understood epigenetic components to this process (Dunoyer et al. 2007). Chlorotic surface-measurements showed that suberoylanilide hydroxamic acid (SAHA) and trichostatine A (TSA), two histone deacetylase inhibitors (HDIs) known to impair TGS, reduce SUL silencing in vitro at 120 parts per million (ppm) (Fig. 1C), with optimal concentrations subsequently determined at 400 and 50 ppm, respectively (Fig. 1D; Supplemental Fig. S1A,B); two additionally tested TSA analogs had similar effects (Supplemental Fig. S2). The levels of SUL siRNAs in SAHA- and TSA-treated SUCSUL seedlings at $100 \mathrm{ppm}$ were nearly identical to those of mock-treated seedlings (Fig. 1E), suggesting that HDls inhibit SUL silencing at, or downstream from, the AGO effector step.

As a second lead to identifying possible modifiers of PTGS, we took into consideration that at least part of the cellular AGO1 pool exists as a peripheral membrane-associated protein (Brodersen et al. 2012), including on the endoplasmic reticulum where AGO1 mediates translational repression and some endonucleolytic cleavage ( $\mathrm{Li}$ et al. 2013; Yu et al. 2017; Freimer et al. 2018). Accordingly, membrane-related processes, autophagy in particular, enhance AGO1 turnover and reduce its function in PTGS, in- cluding under miRNA/siRNA deficient conditions and/or during polerovirus infections (Derrien et al. 2012). Although as yet unconfirmed, similar membrane-related processes may well underlie the lack-of-cargo-induced turnover of AGO4/AGO6 in RdDM mediated by 24-nt siRNAs (Li et al. 2006). Among the 80 "educated guess" molecules tested, Sortin1, which alters plant and yeast vacuolar markers' localization (Zouhar et al. 2004; Rosado et al. 2011), consistently enhanced SUL silencing in vitro at an optimal concentration of $200-400$ ppm (Fig. 1C,D; Supplemental Fig. S1C). This effect was correlated with increased levels of both the 21- and 24-nt SUL siRNA species compared to those of mock-treated seedlings (Fig. 1E). We conclude from this preliminary analysis that the SUC-SULbased experimental system exhibits sufficient consistency and robustness to enable identification of both PTGS suppressors and enhancers.

\section{In vitro identification of robust chemical compounds that enhance the Arabidopsis PTGS pathway}

Having established and validated our experimental settings, a medium-scale screen was initiated with an in-house (Bayer) library of patented or previously described molecules known to influence plant growth and/or adaptation to stress, two processes notoriously regulated by endogenous PTGS pathways (Khraiwesh et al. 2012; Deng et al. 2018; Singh et al. 2018). The identified SUL silencing modifiers were vastly dominated by enhancers representing $\sim 8 \%$ of molecules tested, which we studied in priority; in contrast, only $1.4 \%$ of the molecules were classified as inhibitors (Fig. 2A). Two SUL silencing enhancers, Isoxazolone and [5-(3,4-dichlorophenyl)furan-2-yl]-piperidine-1-ylmethanethione (DFPM), stood out from this focused study due to their robust effects in vitro. At their optimal concentration range (100-350 ppm), these molecules consistently had stronger enhancing effects $(55 \%-$ $60 \%$ normalized chlorosis) than those of Sortin1 at its optimal concentration (35\% normalized chlorosis) used as a reference PTGS-enhancer (Fig. 2B; Supplemental Figs. S1C, S3). Isoxazolone and DFPM also had highly consistent effects in independent large-scale experiments involving each $\geq 75$ individually treated wells of four to five SUCSUL seedlings (Fig. 2C,D, Supplemental Fig. S4). Further attesting to the robustness of these classes of molecules, respectively $88 \%$ and $100 \%$ of Isoxazolone and DFPM chemical analogs tested subsequently increased SUL silencing in seedlings' in vitro treatments, as did $56 \%$ of all Sortin1 analogs tested (Fig. 2E).

\section{Isoxazolone, DFPM, and Sortin1 enhance RNAi in planta}

To investigate if, and to which extent, the in vitro results were transposable in planta, 200 ppm of Isoxazolone, 
A

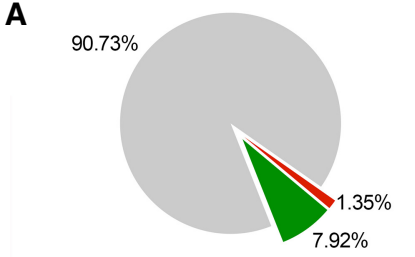

- Inhibitors Enhancers No effect

C

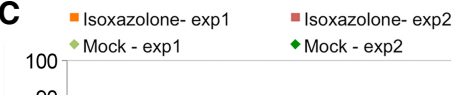

B

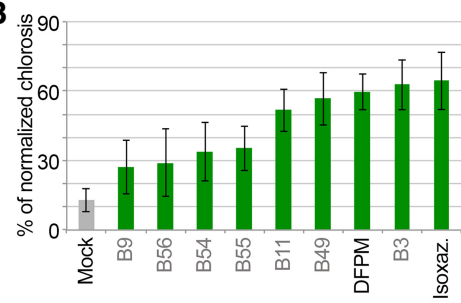

D

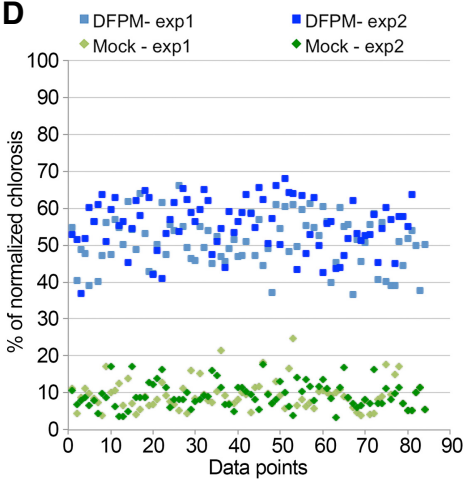

E

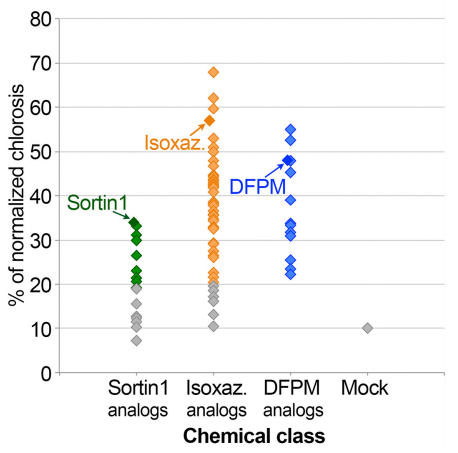

FIGURE 2. Identification of inhibitors and enhancers of the Arabidopsis PTGS pathway, and in vitro validation of the robust effect of Isoxazolone and DFPM. (A) Pie chart representing the classification of all the screened molecules depending on their effect on the SUC-SUL reporter chlorotic phenotype. (B) Percentage of the chlorotic phenotype of SUC-SUL seedlings treated with the best enhancer candidates at 300 ppm selected from all the screened molecules, normalized to the mock treatment. Error bars, mean \pm variation (\%); $N \geq 156$. (C) Percentage of the chlorotic phenotype of SUC-SUL seedlings $7 \mathrm{~d}$ after treatment with mock or Isoxazolone, measured for $\geq 75$ individual wells for two independent experiments (exp1 and exp2), normalized to one mock treatment. (D) Percentage of the chlorotic phenotype of SUC-SUL seedlings $7 \mathrm{~d}$ after treatment with mock or DFPM, measured for $\geq 81$ individual wells for two independent experiments (exp1 and exp2), normalized to one mock treatment. The same sets of mock values (two independent experiments-exp1 and exp2-measured for 84 individual wells) were used for $C$ and $D$. ( $E$ ) Percentage of the chlorotic phenotype of SUC-SUL seedlings $7 \mathrm{~d}$ after treatment with mock, Sortin1, Isoxazolone (Isoxaz.), DFPM, or their chemical analogs (mean from 12 independent biological replicates) normalized to the mock treatment.

DFPM or Sortin1 were sprayed in parallel onto 21-d-old, soil-grown SUC-SUL Arabidopsis plants. The typical veincentered chlorosis in rosette leaves was markedly increased $7 \mathrm{~d}$ posttreatment (dpt) with all three molecules, as compared to mock-treated plants (Fig. 3A). This effect was strictly SUC-SUL transgene-dependent because the SUL mRNA levels remained unaltered in treated nontransgenic plants (Supplemental Fig. S5A). This effect was also likely systemic because it was visible in untreated, new emerging leaves, which contained decreased SUL mRNA levels compared to equivalent leaves of mock-treated plants, in several independent experiments (Fig. 3A-D). Accordingly, the SUL protein showed increasingly reduced levels in systemic leaves of plants sprayed with Sortin1, Isoxazolone and DFPM (Fig. 3E), consistent with their observed enhanced bleaching phenotype compared to mock-treated plants.

\section{Isoxazolone, DFPM, and Sortin1 specifically increase the DCL4 siRNA-processing activity in a probable DRB4-independent manner}

The moderate, intermediate, and stronger SUL silencing respectively mediated by Sortin1, Isoxazolone, and DFPM, correlated with increasingly higher levels of SUL
siRNAs. Moreover, the DCL4-dependent 21-nt species was, accordingly, more loaded into AGO1 in Sortin1-, Isoxazolone- and DFPM-treated compared to mock-treated SUC-SUL rosette leaves, as assessed by immunoprecipitation (IP) with an anti-AGO1 antibody (Fig. 3F). The levels of endogenous DCL1-dependent miRNAs remained, respectively, nearly unchanged in Sortin1- and Isoxazolone-, and slightly enhanced in DFPM-treated samples, an effect also seen in AGO1 IPs (Fig. 3F). This lack of overt effects on total miRNA levels suggests that the gain in 21- and 24-nt SUL siRNAs is not accounted for by an increased activity of DCL1 releasing more dsRNA segments from SUC-SUL transcripts to be used as substrates by DCL4 and DCL3 (Henderson et al. 2006; Dunoyer et al. 2007).

To test if the molecules' effects on the artificial SUC-SUL IR also applied endogenously, we analyzed the 22-nt (DCL2-dependent) and 24-nt (DCL3-dependent) siRNAs derived from the previously characterized IR71 endogenous hairpin (Henderson et al. 2006). The levels of both species were slightly enhanced by the three molecules (Fig.3F). None of the molecules tested strongly enhanced the 24-nt siRNAs to the detriment of the 21-(DCL4, SUC-SUL system) or 22-nt (DCL2, IR71) siRNAs, which is the trademark effect of loss-of-DRB4 function (Dunoyer et al. 2007; Brodersen et al. 2008). An effect on the recently 
A
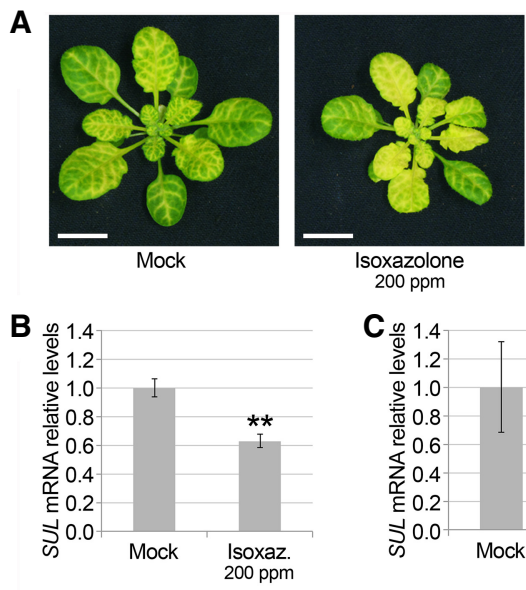

$\mathbf{C}_{\mathscr{0}} 1.4$

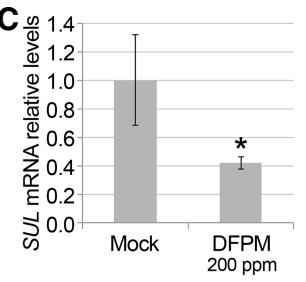

$\mathbf{F}$
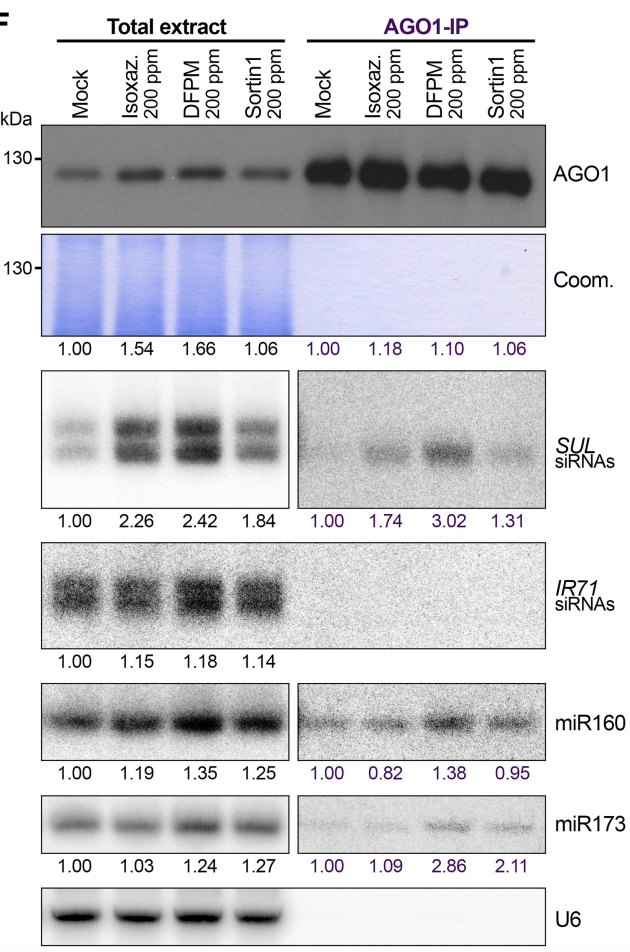
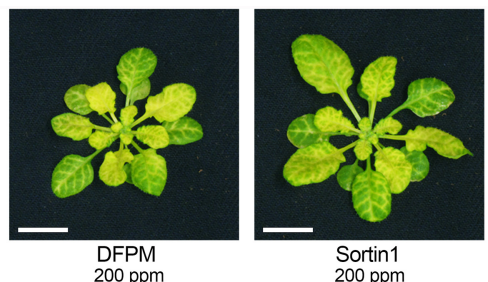

D 1.4

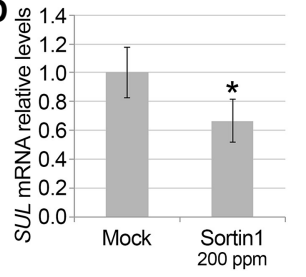

E

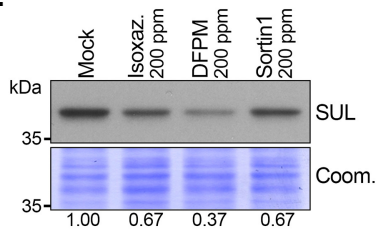

G
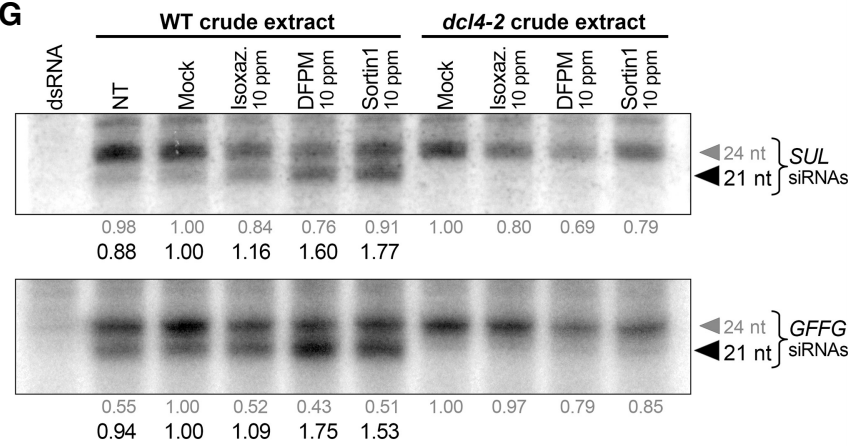

H dc/3-1 crude extract
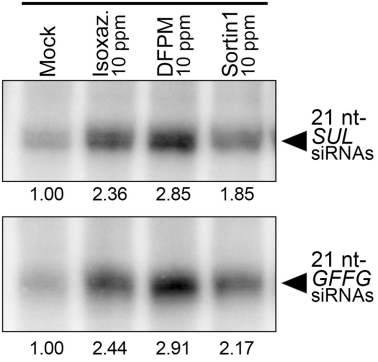

$\begin{array}{llll}1.00 & 2.44 & 2.91 & 2.17\end{array}$

FIGURE 3. In planta validation and molecular analysis of the enhancer effects of Isoxazolone, DFPM, and Sortin1 on sRNA processing and loading. (A) Chlorotic phenotypes of representative SUC-SUL rosettes treated with mock, Isoxazolone, DFPM, or Sortin1. Scale bars: $1 \mathrm{~cm}$. (B-D) qRT-PCR analyses of the SUL mRNA relative levels in SUC-SUL rosettes, treated with mock or Isoxazolone (Isoxaz., B), DFPM (C), or Sortin1 (D). Error bars, mean $\pm 95 \%$ confidence interval; $N=3 .\left(^{* *}\right) P<0.01,\left({ }^{*}\right) P<0.05$ (t-test). (E) Western blot analysis of the SUL protein levels in SUC-SUL rosettes treated with mock, Isoxazolone (Isoxaz.), DFPM, or Sortin1. (Coom.) Coomassie staining used as protein loading control. Relative quantifications of SUL signals normalized to Coom. are indicated below the panels, with 1.00 arbitrary set for mock treatment. Similar results were obtained for two other independent experiments. (F) Western blot analysis of AGO1 total extracts and immunoprecipitates (IP) fractions of SUC-SUL rosettes treated with mock, Isoxazolone (Isoxaz.), DFPM, or Sortin1. (Coom.) Coomassie staining used as protein loading control. Relative quantifications of AGO1 signals are indicated below the panels, with 1.00 arbitrary set for mock treatments. These quantifications are normalized to Coom. in the total extract samples; northern blot analysis of the SUL siRNAs, IR71 siRNAs, miR160, and miR173 in total extracts or in AGO1-IP. (U6) Control for equal RNA loading in total extracts. For SUL siRNAs and IR71 siRNAs, relative quantifications of signals are indicated below the panels, with 1.00 arbitrary set for mock treatments. These quantifications are normalized to U6 in the total extract samples. For SUL siRNAs, miR160 and miR173, shorter or lower exposures of total extract tracks are shown to avoid saturation of signals. Similar results were obtained for one other independent experiment. (G-H) Dicing assays of SUL and GFFG-derived dsRNAs $72 \mathrm{~h}(\mathrm{G})$ or $48 \mathrm{~h}(\mathrm{H})$ after seedlings treatment with mock, Isoxazolone (Isoxaz.), DFPM, or Sortin1. (dsRNA) dsRNA not incubated with crude extract (negative control). (NT) No treatment. Relative quantifications of the 24-nt signals (in gray) or 21-nt signals (in black) are indicated below the panels, with 1.00 arbitrary set for mock treatments. Similar results were obtained for one other independent experiment. 
identified DRB4-antagonists, DRB7.1 and DRB7.2, also is unlikely because both their loss-of-function and overexpression cause molecular signatures on SUL and IR71 siRNAs that are distinctly different from those of the three PTGS-enhancers tested here (Dunoyer et al. 2007; Brodersen et al. 2008; Tschopp et al. 2017). Since DFPM, Isoxazolone and Sortin1 induced neither phytotoxicity nor AtSUC2 promoter activity in treated or systemic AtSUC2-GFP, Col-0, or SUC-SUL rosette leaves (Supplemental Fig. S5B-D), we conclude that these molecules are bona fide, generic and likely DRB4-independent enhancers of IR-PTGS in Arabidopsis.

The three PTGS-enhancers had overall congruent, albeit not identical, effects on the artificial SUC-SUL IR and the endogenous IR71. The differences might be explained by the dissimilar secondary structures and DCL-processing requirements of each $I R$-derived dsRNA, the intrinsic $I R$ derived siRNA steady-state accumulation levels before treatments, and/or, possibly, contrasted IR expression patterns. To investigate and compare side-by-side the molecules' effects more precisely under conditions minimizing biological variations and structural differences, 2-wk-old seedlings grown in vitro were treated in liquid suspension at an effective concentration of 10 ppm (Supplemental Fig. S6). The primary effects of the molecules on de novo processed, as opposed to steady-state, siRNA levels were investigated using "dicing assays" conducted in crude extracts of the treated seedlings. SUL- and GFP-derived long dsRNAs synthesized and labeled in vitro provided independent, standardized sources of DCL substrates in this assay. Processing of both synthetic dsRNAs in extracts of untreated and mock-treated wild-type seedlings led to high and comparatively significantly lower accumulation of a DCL3-dependent 24-nt species and a DCL4-dependent 21-nt species, respectively (Fig. 3G). Strikingly, the 24-nt siRNA levels were reduced and the 21-nt siRNA levels concomitantly increased in the extracts of all PTGS enhancer-treated seedlings, which was confirmed by treatments of $d c / 3$ and $d c / 4$ loss-of-function seedlings (Fig. 3G,H). The treatments of $d c / 4$ mutant extracts also promoted the reduced accumulation of 24-nt siRNA from both GFP and SUL dsRNAs, ruling out that this effect in wild-type extracts results from an enhanced access of DCL4 to dsRNA relative to that of the competing DCL3 protein (Fig. 3G; Henderson et al. 2006).

Because siRNA steady-states are influenced by both their rate of processing and their loading efficacy into AGOs, the above in vitro effects could be due to increased protein levels of DCL4 and/or of AGO1, both of which are predominantly involved in the 21-nt siRNA pathway. Alternatively, or coincidently, the levels of DCL3 and/or AGO4, predominantly involved in the 24-nt siRNA pathway, could be reduced. We thus tested the accumulation of these proteins in DFPM-, Isoxazolone- and Sortin 1 -treated seedlings. We also quantified accumulation of $A G O 2$, known to be induced by chemical and biological stresses (Fátyol et al. 2016) and as a PTGS effector of the 21-nt siRNAs in the SUC-SUL system (data not shown). To simultaneously circumvent cross-hybridization problems encountered with all currently available DCL4 antibodies, we used Arabidopsis transgenic seedlings expressing the DCL4:DCL4-2xFlag-2xHA (DCL4-FHA) construct in the dc/4-2 null genetic background (Supplemental Fig. S7; see Materials and Methods). Following treatments with either PTGS-enhancer, the DCL4-HA and AGO1 levels were nearly unchanged or slightly decreased (Fig. 4A,B; Supplemental Fig. S8A,B), whereas those of DCL3 and AGO4 were consistently and significantly reduced, compared to those found in mock-treated plants (Fig. 4C,D; Supplemental Fig. S8C,D). A specifically increased stability of the 21-nt siRNAs is unlikely because HEN1-mediated 2' O-methylation - the only direct mechanism known to stabilize si/miRNAs in plants-operates on all small RNAs including 24-nt siRNAs (Li et al. 2005; Yu et al. 2005). Additionally, the levels of AGO1-which usually parallel the cellular abundance of its sRNA cargoes (Derrien et al. 2012) — were unchanged or even slightly decreased by the treatments. A specific increase in DCL4 enzymatic activity therefore likely underlies the common effects of the three PTGS-enhancers on dsRNA processing in seedling extracts and in planta.

\section{The effects of DFPM on IR-PTGS are independent of AGO2 protein over-accumulation}

DFPM, unlike Sortin1 or Isoxazolone, consistently increased AGO2 levels (Fig. 4E; Supplemental Fig. S8E) in multiple experiments. Since AGO2, in addition to AGO1, loads 21-nt SUL siRNAs (data not shown), we considered the possibility that parts of the effects of DFPM-the strongest of the enhancers-might relate to this specific property not seen with the other molecules. In order to test if DFPM increases AGO2 expression at the transcriptional level, we used seedlings of a transgenic line in which the AGO2 promoter ( $\mathrm{pAGO}$ ) drives the expression of the GUS reporter gene ( $p A G O 2-G U S$ ). pAGO2-GUS seedlings grown in vitro were thus treated with DFPM for $2 \mathrm{~d}$, or with Bleomycin, a radiomimetic compound that also induces DNA strand breaks in the Arabidopsis genome (Menke et al. 2001). Indeed, Arabidopsis AGO2 transcription was previously shown to be highly induced upon $\gamma$-irradiation, a potent inducer of DNA double-strand break (Wei et al. 2012). While, as expected, GUS expression was induced by bleomycin as attested by histochemical staining, neither mock- nor DFPM-treated seedlings showed enhanced GUS activity (Fig. 4F). These results therefore rule out that the effect of DFPM on AGO2 protein levels are mediated by enhanced AGO2 transcription and suggest, instead, an impact of the molecule at the translational and/or posttranslational level. To measure the requirement for $\mathrm{AGO} 2$ 


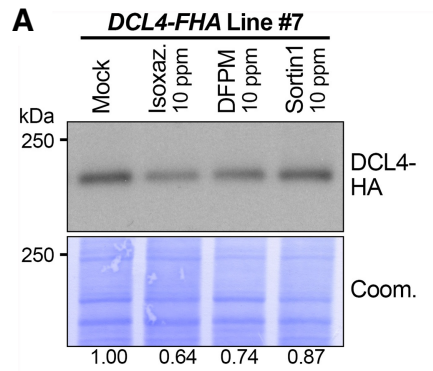

D

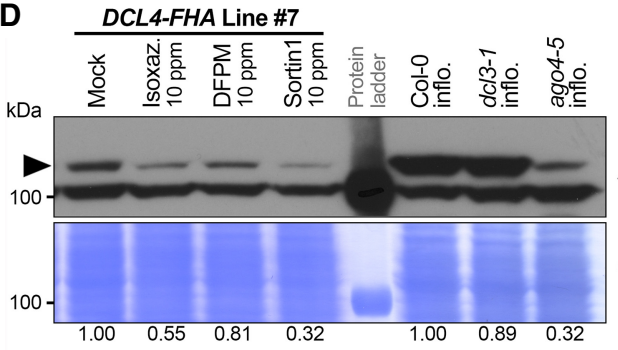

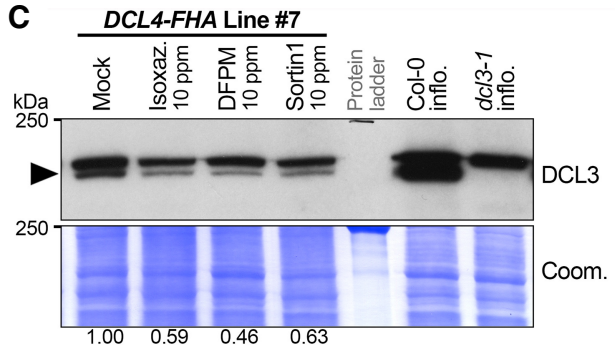

$\mathbf{F}$
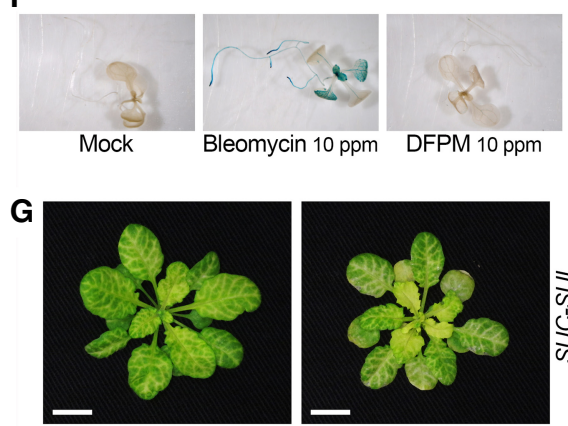

Mock

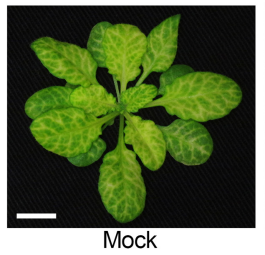

B

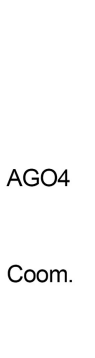

E DCL4-FHA Line \#7
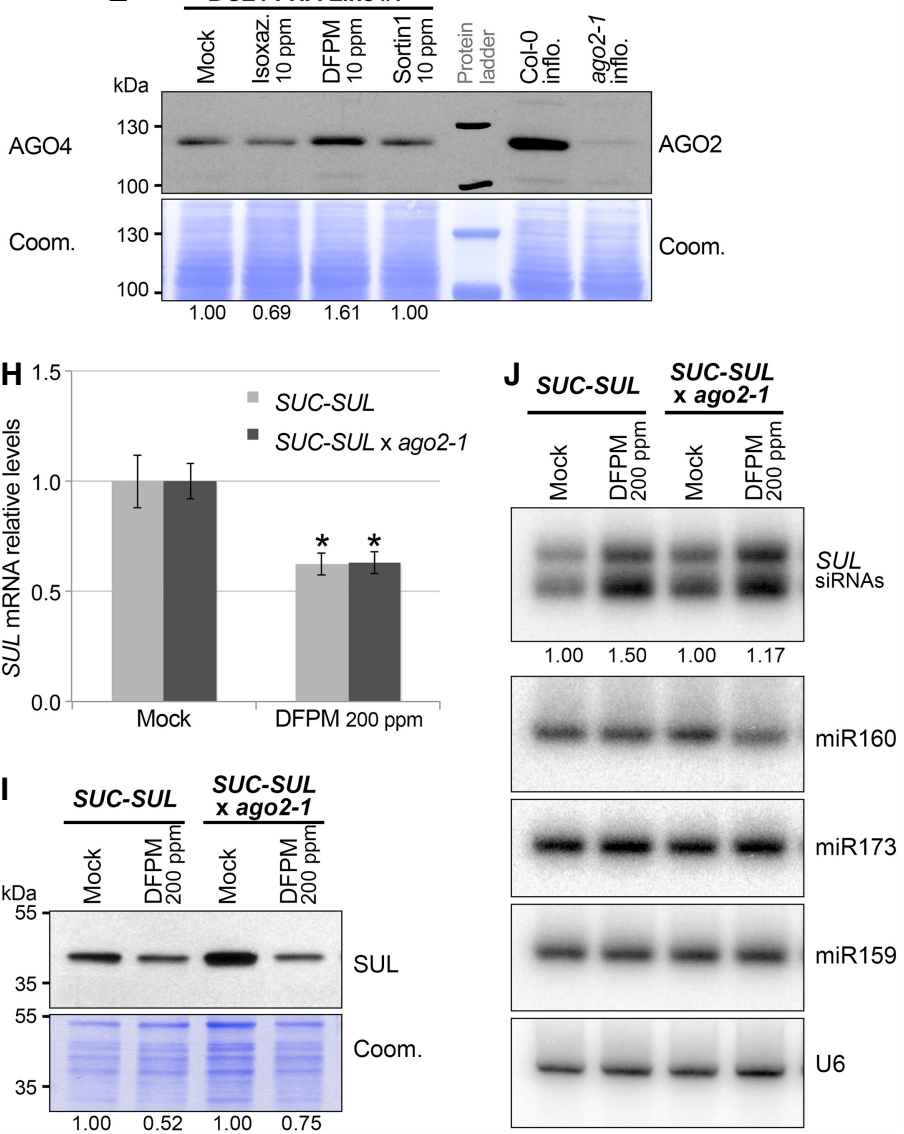

FIGURE 4. Molecular effects of Isoxazolone, DFPM, and Sortin1 on the major silencing effectors. (A-E) Western blot analyses of the DCL4-HA (A), AGO1 (B), DCL3 (C), AGO4 (D), or AGO2 (E) protein levels in DCL4-FHA line \#7 seedlings, $48 \mathrm{~h}$ after treatment with mock, Isoxazolone (Isoxaz.), DFPM, or Sortin1. (Coom.) Coomassie staining used as protein loading control. Relative quantifications of the signals normalized to Coom. are indicated below the panels, with 1.00 arbitrary set for mock treatments. Similar results were obtained for one other independent experiment (see Supplemental Fig. S8). (F) GUS staining of pAGO2-GUS seedlings $2 \mathrm{~d}$ after treatment with mock, Bleomycin (used as positive control), or DFPM. (G) Chlorotic phenotypes of the SUC-SUL WT and SUC-SUL $x$ ago2-1 rosettes $7 \mathrm{~d}$ after treatment with mock or DFPM. White lines indicate the scale bar $(1 \mathrm{~cm})$. (H) qRT-PCR analysis of the SUL mRNA relative levels in SUC-SUL WT and SUC-SUL x ago2-1 rosettes, $7 \mathrm{~d}$ after treatment with mock or DFPM. Error bars, mean $\pm 95 \%$ confidence interval; $N=2$. (*) $P<0.05$ (t-test for comparison between mock and DFPM treatments in each background). (I) Western blot analysis of the SUL protein levels in SUC-SUL WT or SUC-SUL x ago2-1 rosettes, treated with mock or DFPM. (Coom.) Coomassie staining used as protein loading control. Relative quantifications of the SUL signals normalized to Coom. are indicated below the panels, with 1.00 arbitrary set for mock treatments. Similar results were obtained for one other independent experiment. $(J)$ Northern blot analysis of the SUL siRNAs, miR160 and miR173 in SUC-SUL WT and SUC-SUL x ago2-1 rosettes, $7 \mathrm{~d}$ after treatment with mock or DFPM. (U6) Control for equal RNA loading. Relative quantifications of the SUL siRNA signals normalized to U6 are indicated below the panels, with 1.00 arbitrary set for mock treatments. Similar results were obtained for one other independent experiment.

in DFPM-mediated enhancement of IR-PTGS, SUC-SUL plants with an ago2 null-mutant background were treated with DFPM. The increased vein-centered chlorosis and decreased SUL mRNA/protein levels were still observed com- pared to mock-treated plants (Fig. 4G-I). This effect also correlated with increased SUL siRNA levels without any overt effect on miRNAs (Fig. 4J) as previously observed in the SUC-SUL plants with the wild type background 
(Fig. 3F). These results suggest that the elevation in AGO2 levels has little consequence on the DFPM-dependent enhancement of IR-PTGS, hence further supporting DCL4 as being the primarily targeted protein by this and the two other molecules independently of DRB4 or of competitive access to dsRNA compared to DCL3.

\section{Future research and foreseeable applications}

Using Arabidopsis as a model system, our study provides the first proof-of-principle that chemicals can potently and specifically modulate PTGS in a whole organism. The specificity of the enhancers' action is shown by their selective effects on the 21-nt siRNA-mediators of PTGS in standardized dicing assays. Nonetheless, these assays only partially recapitulate in planta applications of the molecules, particularly on the SUL siRNAs for which accumulation of the 24-nt siRNA species was also enhanced, possibly reflecting the complex regulation of this locus including via TGS (Dunoyer et al. 2007). In single-cell organisms, genetic identification of target(s) is the logical step following the isolation of a compound displaying a desirable biological activity. We are, likewise, considering target identification of the most robust of our chemical enhancers, DFPM, via a forward-genetic screen for EMSinduced mutations that suppress its bleaching effects in SUC-SUL seedlings. However, we have not yet reached the stage at which we can confidently rely upon detection of such rare mutants among thousands of sprayed seedings using the automated pipeline described here. Such a screen might be facilitated by increasing the delivery, assimilation, bio-availability and lasting-quality of these molecules with better formulations and targeted chemistry. Indeed some of the Sortin1, Isoxazolone and DFPM analogs identified in this study appear to display even better PTGS-enhancing performances than the cognate starting compounds (Fig. 2E).

Another challenge-beyond the primary scope of this proof-of-concept study -is to test if PTGS-modifiers operate in other plants. Addressing this question will likely require the development of tailored formulation/delivery methods, and might be confounded by the existence of strong genetic modifiers of PTGS in plants, found even among Arabidopsis ecotypes (Vaucheret 2008). Regardless, PTGS-enhancers/suppressors might facilitate Arabidopsis research, first as enabling tools for RNA-silencing studies, but also, more pragmatically, as modulators of phenotypes generated via experimental RNAi in this model species. Indeed, compounds can be delivered at any desired time and confined onto any desired surface by simple spray-application. Their effect is also reversible over time such that even lethal loss-of-function RNAi phenotypes could be potentially studied in single leaves or at specific developmental stages. Last but not least, the ubiquitous defensive role of DCL4-dependent vsiRNAs and amenabil- ity of Arabidopsis to infections by various RNA and DNA viruses now makes it possible to assess the antiviral potential of the three PTGS-enhancers or some of their derivatives. Such studies would nonetheless have to consider potential indirect effects of these compounds on plant basal, as opposed to sequence-specific, defense against pathogens given the strong ties recently uncovered for instance between endo-RNAi and NBS-LRR transcripts regulation (Shivaprasad et al. 2012; Boccara et al. 2014).

\section{MATERIALS AND METHODS}

\section{Plant material}

Arabidopsis thaliana ecotype Columbia-O (Col-0) was used as wildtype (WT) control. dc/3-1, dc/4-2, and ago2-1 Arabidopsis mutants have been previously described (Xie et al. 2004, 2005; Lobbes et al. 2006). SUC-SUL in Col-O has been already described (Dunoyer et al. 2005), as well as AtSUC-GFP in Col-0 (Imlau et al. 1999). For DCL4-FHA transgenic lines \#6 and \#7, Arabidopsis DCL4 promoter was amplified from Col-0 genomic DNA with pDCL4-attB4 and pDCL4-attB1r primers (Supplemental Table S1) and inserted into pDONR4-1r via Gateway BP recombination. Arabidopsis DCL4 CDS (genomic) was amplified with the DCL4attB1 and DCL4-attB2 primers (Supplemental Table S1) and inserted into pDONR221 via BP recombination. 2xFlag-2xHA was amplified with the 2Flag2HA-attB2r and 2Flag2HA-attB3 primers (Supplemental Table S1) and inserted into pDONR2r-3 via BP recombination. DCL4 promoter, DCL4 CDS, and 2xFlag-2xHA tag sequences were fused by three-way $L R$ recombination into pB7m34GW and the final construct was transformed into Col-0 (line \#6) or dcl4-2 Arabidopsis mutant (line \#7). Lines \#6 and \#7, which were selected based on their segregation ratio on Basta containing MS and homozygous T3, were used. For pAGO2GUS transgenic line, Arabidopsis AGO2 promoter was amplified from Col-0 genomic DNA with pAGO2-attB4 and pAGO2-attB1r primers (Supplemental Table S1) and inserted into pDONR4-1r via Gateway BP recombination. GUS was amplified from the binary vector pMDC162 with the GUS_attB2r and GUS_attB3 primers (Supplemental Table S1) and inserted into pDONR2r-3 via BP recombination. 2xFlag-2xHA tag was synthetized into pDONR221 (Thermo Fisher Scientific). A three-way LR recombination was performed into the binary vector $\mathrm{pB} 7 \mathrm{~m} 34 \mathrm{GW}$ to fuse the AGO2 promoter, 2xFlag-2xHA and GUS, and the final construct was transformed into Col-0. Based on their segregation ratio on Basta containing MS, homozygous T3 were used.

\section{Plant growth and treatment conditions}

To set up the experimental design, Arabidopsis seedlings were grown in vitro under 96-well plate format (four-five seedlings/ well), on $180 \mu \mathrm{L}$ of MS-agar medium in growth cabinet with the following conditions: $70 \%$ humidity, $24^{\circ} \mathrm{C}$, continuous light of $60 \mu$ Einstein. $\mathrm{m}^{-2} \cdot \mathrm{s}^{-1}$. Seedlings were sprayed at day 7 after germination with $5 \mu \mathrm{L}$ of solution containing $50-400$ ppm of active molecules, 5\% DMSO and EC Premix (Bayer), using an automated liquid handling Lissy platform (Zinsser). The treatment effects on SUC-SUL plants were recorded digitally under MacroFluo 
macroscope (Leica) and quantified at day 14 by measuring the total chlorotic zone for each well with the MetaMorph software (Molecular Devices). Wells with seedlings of visually bad quality (germination or chlorotic variability) were excluded from the analyses. An average of the chlorotic zone from a minimum of four individual replicates (wells) was calculated, as well as a $95 \%$ confidence interval for each molecule. The quantification script threshold was adjusted for each plate to obtain an average of $10 \%$ of chlorotic zone for the mock treatment containing $5 \%$ DMSO and EC Premix. Subsequent chemical libraries were screened at 300 ppm with the same conditions as described above. Molecules with a putative effect on the chlorotic phenotype of the SUC-SUL plants, but with little or no effect on the AtSUC2-GFP plants (chlorosis, GFP phenotype), were next subjected to a dose-range test (from 18 ppm up to 400 ppm). An average of the chlorotic zone from a minimum of four individual replicates (wells) was calculated, as well as a 95\% confidence interval for each molecule and each dose. Seedlings from 96 wells were harvested and pooled just after chlorosis quantification for molecular analyses.

For the dicing assays and western blot analyses, Arabidopsis seedlings were grown in vitro on MS-agar medium, pH 5.7 (MS including vitamins and MES, $5 \mathrm{~g} / \mathrm{L}$ sucrose, $8 \mathrm{~g} / \mathrm{L}$ Microagar Duchefa) in growth cabinet with the following conditions: $50 \%$ humidity, $21^{\circ} \mathrm{C}, 12 \mathrm{~h}$ light of $30 \mu$ Einstein. $\mathrm{m}^{-2} \cdot \mathrm{s}^{-1} / 12 \mathrm{~h}$ dark photoperiod. Twelve-day-old seedlings were transferred into liquid MS in 6-well plates ( 30 seedlings/well) for $48 \mathrm{~h}$ before treatment by adding the molecules directly into the medium to a final concentration of $10 \mathrm{ppm}$. Seedlings were harvested $48 \mathrm{~h}$ or $72 \mathrm{~h}$ after treatment (one well/replicate) for molecular analyses.

For experiments performed on rosettes, Arabidopsis plants were grown on soil in growth cabinet with the following conditions: $60 \%$ humidity, $21^{\circ} \mathrm{C}, 16 \mathrm{~h}$ light $/ 8 \mathrm{~h}$ dark photoperiod. Molecules were resuspended in DMSO, diluted from 100 ppm to 200 ppm in water containing EC Premix, and sprayed on 4wk-old rosettes using the EcoSpray system (Labo-Chimie France) to allow complete coverage of the leaf surface. New growth aerial tissues of four rosettes were harvested and pooled at $7 \mathrm{dpt}$ for molecular analyses.

\section{GUS staining}

Briefly, treated seedlings were first fixed for $20 \mathrm{~min}$ in $90 \%$ acetone, and subsequently stained with $50 \mathrm{mM}$ sodium phosphate (pH 7.2), $2 \mathrm{mM}$ potassium ferrocyanide, $2 \mathrm{mM}$ potassium ferricyanide, $0.2 \%$ Triton $\mathrm{X}-100$, and $2 \mathrm{mM} \mathrm{X-Gluc} \mathrm{(Roth)} \mathrm{at} 37^{\circ} \mathrm{C}$ in dark overnight. Staining solution was removed by ethanol washes.

\section{RNA extraction}

Total RNA was extracted from frozen, ground Arabidopsis tissues using Isol-RNA Lysis reagent (5-PRIME) according to the manufacturer's instructions.

\section{Real-time qRT-PCR analyses}

Total RNA was treated with DNase I (Thermo Fisher Scientific) for $50 \mathrm{~min}$ at $37^{\circ} \mathrm{C}$ before reverse transcription with the RevertAid
First Strand cDNA Synthesis Kit (Thermo Fisher Scientific). Realtime GPCR was performed on a LightCycler480 II (Roche) with the KAPA SYBR FAST qPCR Kit (KAPA Biosystems) and gene-specific primers (Supplemental Table S2). PCR was done in 384-well optical reaction plates heated at $95^{\circ} \mathrm{C}$ for $10 \mathrm{~min}$, followed by 45 cycles of denaturation at $95^{\circ} \mathrm{C}$ for $15 \mathrm{sec}$, annealing at $60^{\circ} \mathrm{C}$ for $20 \mathrm{sec}$, and elongation at $72^{\circ} \mathrm{C}$ for $40 \mathrm{sec}$. A melting curve was performed at the end of the amplification by steps of $1^{\circ} \mathrm{C}$ (from $50^{\circ} \mathrm{C}$ to $95^{\circ} \mathrm{C}$ ). Threshold cycle $\left(C_{t}\right)$ values were determined by calculating the second derivative maximum of three technical replicates per sample. Relative expression levels were calculated by subtracting the average $C_{t}$ values for the genes of interest to those of At4g26410 (Czechowski et al. 2005) (to give $\Delta C_{t}$ ) and then calculating " $2^{\Delta C t}$ ". Normal distributions were confirmed by Shapiro-Wilk test $(\alpha=0.02)$. Equal variances were tested by F-test ( $95 \%$ confidence interval). P-values were calculated using t-test (one-tailed distribution and two-sample unequal variance if the equal variance was not validated; one-tailed distribution and two-sample equal variance if the equal variance was validated).

\section{RNA blot analyses}

Northern analyses of low molecular weight RNA were performed with $10-50 \mu \mathrm{g}$ of total RNA diluted in $50 \%$ formamide. Total RNA was separated in $0.5 \times$ TBE on a $17.5 \%$ polyacrylamide-urea gel, electrotransferred in $0.5 \times$ TBE to a HyBond-NX membrane (GE Healthcare Life Sciences) and crosslinked with 1-ethyl-3-(3dimethylaminopropyl) carbodiimide (Sigma-Aldrich)—mediated chemical crosslinking for $90 \mathrm{~min}$, as previously described (Pall and Hamilton 2008). RNA blots were prehybridized in PerfectHyb Plus Hybridization Buffer (Sigma-Aldrich) at $42^{\circ} \mathrm{C}$ for 30 min before adding probes of interest. Random-radiolabeled probes (Supplemental Table S3) were generated by incubating PCR fragments with the Prime-a-Gene labeling system (Promega) in the presence of $\left[\alpha_{-}{ }^{32} \mathrm{P}\right]-\mathrm{dCTP}$ (Hartmann Analytic). Oligonucleotide probes (Supplemental Table S4) were end labeled by incubation with T4 PNK (Thermo Fisher Scientific) in the presence of $\left[\gamma_{-}{ }^{32} \mathrm{P}\right]-\mathrm{dATP}$ (Hartmann Analytic). Membranes were probed overnight at $42^{\circ} \mathrm{C}$ and then washed three times with $2 \times \mathrm{SSC}, 2 \% \mathrm{SDS}$ at $50^{\circ} \mathrm{C}$. Radiolabelled signals were detected either by autoradiography (x-ray films) or by phosphor-imaging scanning on a Typhoon FLA900 (GE Healthcare Life Science). Membranes were probed several times with multiple sequences after stripping with boiling $0.1 \%$ SDS. U6 was probed together with miR173 in Figure 3F or miR159 in Figure 4J, though different exposure times (Fig. 3F) or levels (Fig. 4J) were used to prepare the figures. Signal intensities were quantified using ImageJ software (http://imagej.nih.gov/ij).

\section{Total protein extractions and western blot analyses}

For SUL and GFP protein analyses, total proteins were precipitated overnight from the phenolic phase of the Isol-RNA Lysis in 75\% ice-cold acetone, washed twice with $80 \%$ ice-cold acetone and resuspended in 3\% SDS, $62.5 \mathrm{mM}$ Tris- $\mathrm{HCl}, \mathrm{pH} 6.8,10 \%$ glycerol $(\mathrm{v} / \mathrm{v})$. For HA, AGO1, AGO2, AGO4, and DCL3 protein analysis, total proteins were extracted by following the Tanaka method (Hurkman and Tanaka 1986). 
Protein concentrations were determined by a modified Lowry procedure using the DC Protein Assay Kit (Bio-Rad). Proteins were resolved by SDS-PAGE and electro-transferred to Immobilon-P PVDF membrane (Millipore). Following $1 \mathrm{~h}$ blocking step in $1 \times$ TBS $+0.1 \%$ Tween-20 supplemented with $5 \%$ nonfat dry milk, antibody incubations were carried out overnight at $4{ }^{\circ} \mathrm{C}$ with constant shaking. Primary antibodies were used following dilutions in Supplemental Table S5. Membranes were next washed three times in TBS + 0.1\% Tween-20, and subsequently incubated for $1 \mathrm{~h}$ with HRP-conjugated goat anti-rabbit antibodies (except for $\mathrm{HA}$ detection), then rinsed three times before detection with ECL Western Blotting Detection Kit (GE Healthcare Life Science). Membranes were finally stained with Coomassie blue for equal loading control. Signal intensities were quantified using ImageJ software (http://imagej.nih.gov/ij).

\section{Immunoprecipitations (IPs)}

Arabidopsis ground tissues were mixed $1 / 3(\mathrm{~g} / \mathrm{mL})$ with IP buffer (50 mM Tris- $\mathrm{HCl}$, pH 7.5, $150 \mathrm{mM} \mathrm{NaCl}, 10 \%$ glycerol, 0.1\% NP40) containing $2 \mu \mathrm{M}$ proteasome inhibitor MG-132 and cOmplete protease inhibitor cocktail (Roche), and incubated for $30 \mathrm{~min}$ at $4^{\circ} \mathrm{C}$ on a rotating wheel. All the following steps were performed at $4^{\circ} \mathrm{C}$ or on ice. Cell debris were removed by centrifugation for $30 \mathrm{~min}$ at $8000 \mathrm{~g}$. Supernatant was precleared by incubating for $1 \mathrm{~h}$ with $30 \mu \mathrm{L}$ of Protein A-agarose beads (Sigma). Beads were removed by centrifugation for $1 \mathrm{~min}$ at $1500 \mathrm{~g}$, and supernatant was incubated with anti-AGO1 antibody at 1/500 dilution for $1 \mathrm{~h}$. $30 \mu \mathrm{L}$ Protein A-agarose beads were added for $1 \mathrm{~h}$ and $30 \mathrm{~min}$. Beads were pelleted, washed three times in IP buffer, and resuspended in $1 \mathrm{~mL}$ of Isol-RNA Lysis reagent. Both RNA and proteins were extracted, as previously described.

\section{Dicing assays}

SUL-derived sequences were prepared from Col-0 gDNA. GFFGderived sequences were amplified from a eGFP containing vector (pK7WGF2). Sense and antisense sequences were amplified using primers containing the T7 promoter sequence (Supplemental Table S6) and in vitro transcribed into RNA by T7 RNA polymerase (Thermo Fisher Scientific) in the presence of $\left[\alpha^{32}\right.$ P]-CTP (Hartmann Analytic). Remaining DNA was removed by DNAse treatment (Thermo Fisher Scientific). Transcripts were cleaned first on a mini Quick Spin Columns (Roche) and subsequently by phenol-chloroform extraction. Equal amounts of sense and antisense ${ }^{32} \mathrm{P}$-labeled RNAs were annealed in annealing buffer (10 mM Tris$\mathrm{HCl} \mathrm{pH} \mathrm{7.5,100} \mathrm{mM} \mathrm{NaCl)} \mathrm{by} \mathrm{placing} \mathrm{the} \mathrm{tubes} \mathrm{in} \mathrm{a} \mathrm{heating} \mathrm{block}$ preheated at $95^{\circ} \mathrm{C}$ until cooling down to room-temperature. The quality of the dsRNAs was verified by loading $1 \mu \mathrm{L}$ onto a $5 \%$ native acrylamide gel.

In vitro dicing assays were performed, as previously described (Qi et al. 2005). Arabidopsis seedlings were ground into fine powder with liquid nitrogen and homogenized into extraction buffer (1 $\mathrm{g} / \mathrm{mL}-20 \mathrm{mM}$ Tris- $\mathrm{HCl}, 4 \mathrm{mM} \mathrm{MgCl}, \mathrm{pH}$ 7.5) containing $5 \mathrm{mM}$ DTT and protease inhibitor cocktail (Roche). Cell debris were removed by centrifugation at $22,000 \mathrm{~g}$ at $4^{\circ} \mathrm{C}$ for $20 \mathrm{~min}$. The supernatant was collected and total protein concentration was determined using the DC Protein Assay Kit (Bio-Rad) before being diluted to $0.5 \mathrm{mg} / \mathrm{mL}$.
${ }^{32} \mathrm{P}$-labeled dsRNAs (around 50,000 counts per min) were incubated for $2 \mathrm{~h}$ at $25^{\circ} \mathrm{C}$ in a $20 \mu \mathrm{L}$ reaction containing $15 \mu \mathrm{L}$ of crude extract (10-20 $\mu \mathrm{g}$ of total protein) and $4 \mu \mathrm{L}$ of $5 \times$ Dicer reaction buffer $(0.5 \mathrm{M} \mathrm{NaCl}, 5 \mathrm{mM}$ ATP, $1 \mathrm{mM} \mathrm{GTP}, 6 \mathrm{mM} \mathrm{MgCl}$, 125 $\mathrm{mM}$ creatine phosphate, $150 \mu \mathrm{g} / \mathrm{mL}$ creatine kinase and 2 units RNase Inhibitor). The reaction was stopped by adding $250 \mu \mathrm{L}$ of Isol-RNA Lysis reagent and RNA was extracted according to the manufacturer's instructions, with addition of glycogen during the RNA precipitation step. RNA was resuspended in formamide $50 \%$, resolved on a $15 \%$ denaturing PAGE gel, electrotransferred to a HyBond-NX membrane (GE Healthcare Life Science) and crosslinked by UV irradiation. Radiolabelled signals were detected by phosphor-imaging scanning on a Typhoon FLA900 (GE Healthcare Life Science).

\section{SUPPLEMENTAL MATERIAL}

Supplemental material is available for this article.

\section{ACKNOWLEDGMENTS}

We thank Catherine Perrier, Frederic Schmitt, and Rachel Baltz for their help in setting up the collaboration between ETH-Zürich and Bayer S.A.S. We also thank Hervé Vaucheret for providing SUCSUL $x$ ago2-1 seeds, Nathan Pumplin for providing DCL4-FHA transgenic lines, and André Imboden for maintaining Arabidopsis standings on soil. This work was supported by European Research Council (ERC) advanced grant "Frontiers of RNAi-II" to O.V. (no. 323071).

Received September 20, 2018; accepted June 2, 2019.

\section{REFERENCES}

Adenot X, Elmayan T, Lauressergues D, Boutet S, Bouché N, Gasciolli V, Vaucheret H. 2006. DRB4-dependent TAS3 trans-acting siRNAs control leaf morphology through AGO7. Curr Biol 16: 927-932. doi:10.1016/j.cub.2006.03.035

Boccara M, Sarazin A, Thiébeauld O, Jay F, Voinnet O, Navarro L, Colot V. 2014. The Arabidopsis miR472-RDR6 silencing pathway modulates PAMP- and effector-triggered immunity through the post-transcriptional control of disease resistance genes. PLOS Pathog 10: e1003883. doi:10.1371/journal.ppat.1003883

Bohmert K, Camus I, Bellini C, Bouchez D, Caboche M, Benning C. 1998. AGO1 defines a novel locus of Arabidopsis controlling leaf development. EMBO J 17: 170-180. doi:10.1093/emboj/17 .1 .170

Bologna NG, Voinnet O. 2014. The diversity, biogenesis, and activities of endogenous silencing small RNAs in Arabidopsis. Annu Rev Plant Biol 65: 473-503. doi:10.1146/annurev-arplant050213-035728

Bologna NG, Iselin R, Abriata LA, Sarazin A, Pumplin N, Jay F, Grentzinger T, Dal Peraro M, Voinnet O. 2018. Nucleo-cytosolic shuttling of ARGONAUTE1 prompts a revised model of the plant microRNA pathway. Mol Cell 69: 709-719 e705. doi:10.1016/j .molcel.2018.01.007

Brodersen P, Sakvarelidze-Achard L, Bruun-Rasmussen M, Dunoyer P, Yamamoto YY, Sieburth L, Voinnet O. 2008. Widespread translational inhibition by plant miRNAs and siRNAs. Science 320: 1185-1190. doi:10.1126/science.1159151 
Brodersen P, Sakvarelidze-Achard L, Schaller H, Khafif M, Schott G, Bendahmane A, Voinnet O. 2012. Isoprenoid biosynthesis is required for miRNA function and affects membrane association of ARGONAUTE 1 in Arabidopsis. Proc Natl Acad Sci 109: 17781783. doi:10.1073/pnas.1112500109

Chitwood DH, Nogueira FT, Howell MD, Montgomery TA, Carrington JC, Timmermans MC. 2009. Pattern formation via small RNA mobility. Genes Dev 23: 549-554. doi:10.1101/gad.1770009

Cuerda-Gil D, Slotkin RK. 2016. Non-canonical RNA-directed DNA methylation. Nat Plants 2: 16163. doi:10.1038/nplants.2016.163

Czechowski T, Stitt M, Altmann T, Udvardi MK, Scheible WR. 2005. Genome-wide identification and testing of superior reference genes for transcript normalization in Arabidopsis. Plant Physiol 139: 5-17. doi:10.1104/pp.105.063743

Deleris A, Gallego-Bartolome J, Bao J, Kasschau KD, Carrington JC, Voinnet O. 2006. Hierarchical action and inhibition of plant Dicer-like proteins in antiviral defense. Science 313: 68-71. doi:10.1126/science.aaf2336

Deng P, Muhammad S, Cao M, Wu L. 2018. Biogenesis and regulatory hierarchy of phased small interfering RNAs in plants. Plant Biotechnol J 16: 965-975.

Derrien B, Baumberger N, Schepetilnikov M, Viotti C, De Cillia J, Ziegler-Graff V, Isono E, Schumacher K, Genschik P. 2012. Degradation of the antiviral component ARGONAUTE1 by the autophagy pathway. Proc Natl Acad Sci 109: 15942-15946. doi:10.1073/pnas.1209487109

Dinh TT, Gao L, Liu XG, Li DM, Li SB, Zhao YY, O'Leary M, Le B, Schmitz RJ, Manavella P, et al. 2014. DNA topoisomerase $1 \alpha$ promotes transcriptional silencing of transposable elements through DNA methylation and histone lysine 9 dimethylation in Arabidopsis. PLos Genet 10: e1004446. doi:10.1371/journal .pgen.1004446

Dunoyer P, Himber C, Voinnet O. 2005. DICER-LIKE 4 is required for RNA interference and produces the 21-nucleotide small interfering RNA component of the plant cell-to-cell silencing signal. Nat Genet 37: 1356-1360. doi:10.1038/ng1675

Dunoyer P, Himber C, Ruiz-Ferrer V, Alioua A, Voinnet O. 2007. Intraand intercellular RNA interference in Arabidopsis thaliana requires components of the microRNA and heterochromatic silencing pathways. Nat Genet 39: 848-856. doi:10.1038/ng2081

Fátyol K, Ludman M, Burgyán J. 2016. Functional dissection of a plant Argonaute. Nucleic Acids Res 44: 1384-1397. doi:10.1093/nar/ gkv1371

Freimer JW, Hu TJ, Blelloch R. 2018. Decoupling the impact of microRNAs on translational repression versus RNA degradation in embryonic stem cells. eLife 7: e38014. doi:10.7554/eLife.38014

Gasciolli V, Mallory AC, Bartel DP, Vaucheret H. 2005. Partially redundant functions of Arabidopsis DICER-like enzymes and a role for DCL4 in producing trans-acting siRNAs. Curr Biol 15: 14941500. doi:10.1016/j.cub.2005.07.024

Haas G, Azevedo J, Moissiard G, Geldreich A, Himber C, Bureau M, Fukuhara T, Keller M, Voinnet O. 2008. Nuclear import of CaMV P6 is required for infection and suppression of the RNA silencing factor DRB4. EMBO J 27: 2102-2112. doi:10.1038/emboj.2008 .129

Henderson IR, Zhang X, Lu C, Johnson L, Meyers BC, Green PJ, Jacobsen SE. 2006. Dissecting Arabidopsis thaliana DICER function in small RNA processing, gene silencing and DNA methylation patterning. Nat Genet 38: 721-725. doi:10.1038/ng1804

Hicks GR, Robert S. 2014. Plant chemical genomics: methods and protocols foreword. Humana Press, New York.

Hiraguri A, Itoh R, Kondo N, Nomura Y, Aizawa D, Murai Y, Koiwa H, Seki M, Shinozaki K, Fukuhara T. 2005. Specific interactions between Dicer-like proteins and HYL1/DRB-family dsRNA-binding proteins in Arabidopsis thaliana. Plant Mol Biol 57: 173-188. doi:10.1007/s11103-004-6853-5

Hurkman WJ, Tanaka CK. 1986. Solubilization of plant membrane proteins for analysis by two-dimensional gel electrophoresis. Plant Physiol 81: 802-806. doi:10.1104/pp.81.3.802

Imlau A, Truernit E, Sauer N. 1999. Cell-to-cell and long-distance trafficking of the green fluorescent protein in the phloem and symplastic unloading of the protein into sink tissues. Plant Cell 11: 309-322. doi:10.1105/tpc.11.3.309

Khraiwesh B, Zhu JK, Zhu J. 2012. Role of miRNAs and siRNAs in biotic and abiotic stress responses of plants. Biochim Biophys Acta 1819: 137-148. doi:10.1016/j.bbagrm.2011.05.001

Li JJ, Yang ZY, Yu B, Liu J, Chen XM. 2005. Methylation protects miRNAs and siRNAs from a 3 '-end uridylation activity in Arabidopsis. Curr Biol 15: 1501-1507. doi:10.1016/j.cub.2005 .07 .029

Li CF, Pontes O, El-Shami M, Henderson IR, Bernatavichute $\mathrm{YV}$, Chan SW, Lagrange T, Pikaard CS, Jacobsen SE. 2006. An ARGONAUTE4-containing nuclear processing center colocalized with Cajal bodies in Arabidopsis thaliana. Cell 126: 93-106. doi:10.1016/j.cell.2006.05.032

Li Y, Lu J, Han Y, Fan X, Ding SW. 2013. RNA interference functions as an antiviral immunity mechanism in mammals. Science 342: 231 234. doi:10.1126/science.1241911

Lobbes D, Rallapalli G, Schmidt DD, Martin C, Clarke J. 2006. SERRATE: a new player on the plant microRNA scene. EMBO Rep 7: 1052-1058. doi:10.1038/sj.embor.7400806

Menke M, Chen I, Angelis KJ, Schubert I. 2001. DNA damage and repair in Arabidopsis thaliana as measured by the comet assay after treatment with different classes of genotoxins. Mutat Res 493: 8793. doi:10.1016/S1383-5718(01)00165-6

Pall GS, Hamilton AJ. 2008. Improved northern blot method for enhanced detection of small RNA. Nat Protoc 3: 1077-1084. doi:10.1038/nprot.2008.67

Poethig RS, Peragine A, Yoshikawa M, Hunter C, Willmann M, Wu G. 2006. The function of RNAi in plant development. Cold Spring Harb Symp Quant Biol 71: 165-170. doi:10.1101/sqb.2006.71 .030

Qi Y, Denli AM, Hannon GJ. 2005. Biochemical specialization within Arabidopsis RNA silencing pathways. Mol Cell 19: 421-428. doi:10.1016/j.molcel.2005.06.014

Rosado A, Hicks GR, Norambuena L, Rogachev I, Meir S, Pourcel L, Zouhar J, Brown MQ, Boirsdore MP, Puckrin RS, et al. 2011. Sortin1-hypersensitive mutants link vacuolar-trafficking defects and flavonoid metabolism in Arabidopsis vegetative tissues. Chem Biol 18: 187-197. doi:10.1016/j.chembiol.2010.11.015

Schwab R, Maizel A, Ruiz-Ferrer V, Garcia D, Bayer M, Crespi M, Voinnet O, Martienssen RA. 2009. Endogenous TasiRNAs mediate non-cell autonomous effects on gene regulation in Arabidopsis thaliana. PLoS One 4: e5980. doi:10.1371/journal pone.0005980

Shivaprasad PV, Chen HM, Patel K, Bond DM, Santos BA, Baulcombe DC. 2012. A microRNA superfamily regulates nucleotide binding site-leucine-rich repeats and other mRNAs. Plant Cell 24: 859-874. doi:10.1105/tpc.111.095380

Singh A, Gautam V, Singh S, Sarkar Das S, Verma S, Mishra V, Mukherjee S, Sarkar AK. 2018. Plant small RNAs: advancement in the understanding of biogenesis and role in plant development. Planta 248: 545-558.

Szittya G, Burgyán J. 2013. RNA interference-mediated intrinsic antiviral immunity in plants. Curr Top Microbiol Immunol 371: 153181. doi:10.1007/978-3-642-37765-5_6

Tschopp MA, Iki T, Brosnan CA, Jullien PE, Pumplin N. 2017. A complex of Arabidopsis DRB proteins can impair dsRNA processing. RNA 23: 782-797. doi:10.1261/rna.059519.116 


\section{Jay et al.}

Vaucheret H. 2008. Plant ARGONAUTES. Trends Plant Sci 13: 350 358. doi:10.1016/j.tplants.2008.04.007

Vazquez F, Gasciolli V, Crété P, Vaucheret H. 2004. The nuclear dsRNA binding protein HYL1 is required for microRNA accumulation and plant development, but not posttranscriptional transgene silencing. Curr Biol 14: 346-351. doi:10.1016/j.cub 2004.01.035

Wei W, Ba Z, Gao M, Wu Y, Ma Y, Amiard S, White Cl, Rendtlew Danielsen JM, Yang YG, Qi Y. 2012. A role for small RNAs in DNA double-strand break repair. Cell 149: 101-112. doi:10 .1016/j.cell.2012.03.002

Xie Z, Johansen LK, Gustafson AM, Kasschau KD, Lellis AD, Zilberman D, Jacobsen SE, Carrington JC. 2004. Genetic and functional diversification of small RNA pathways in plants. PLOS Biol 2: E104. doi:10.1371/journal.pbio.0020104

Xie Z, Allen E, Wilken A, Carrington JC. 2005. DICER-LIKE 4 functions in trans-acting small interfering RNA biogenesis and vegetative phase change in Arabidopsis thaliana. Proc Natl Acad Sci 102: 12984-12989. doi:10.1073/pnas.0506426102

Yu B, Yang ZY, Li JJ, Minakhina S, Yang MC, Padgett RW, Steward R, Chen XM. 2005. Methylation as a crucial step in plant microRNA biogenesis. Science 307: 932-935. doi:10.1126/science.1107130

Yu Y, Ji L, Le BH, Zhai J, Chen J, Luscher E, Gao L, Liu C, Cao X, Mo B, et al. 2017. ARGONAUTE10 promotes the degradation of miR165/ 6 through the SDN1 and SDN2 exonucleases in Arabidopsis. PLoS Biol 15: e2001272. doi:10.1371/journal.pbio.2001272

Zhang HM, Deng XY, Miki D, Cutler S, La HG, Hou YJ, Oh J, Zhu JK. 2012. Sulfamethazine suppresses epigenetic silencing in Arabidopsis by impairing folate synthesis. Plant Cell 24: 12301241. doi:10.1105/tpc.112.096149

Zouhar J, Hicks GR, Raikhel NV. 2004. Sorting inhibitors (Sortins): chemical compounds to study vacuolar sorting in Arabidopsis. Proc Natl Acad Sci 101: 9497-9501. doi:10.1073/pnas.04021 21101 

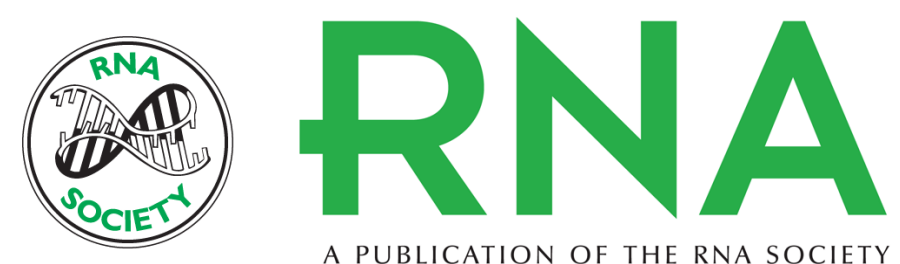

A PUBLICATION OF THE RNA SOCIETY

\section{Chemical enhancers of posttranscriptional gene silencing in Arabidopsis}

Florence Jay, Maxime Vitel, Florian Brioudes, et al.

RNA 2019 25: 1078-1090 originally published online June 4, 2019

Access the most recent version at doi:10.1261/rna.068627.118

\section{Supplemental http://rnajournal.cshlp.org/content/suppl/2019/06/04/rna.068627.118.DC1 \\ Material}

References This article cites 48 articles, 18 of which can be accessed free at: http://rnajournal.cshlp.org/content/25/9/1078.full.html\#ref-list-1

Creative This article is distributed exclusively by the RNA Society for the first 12 months after the Commons

License full-issue publication date (see http://rnajournal.cshlp.org/site/misc/terms.xhtml). After 12 months, it is available under a Creative Commons License (Attribution-NonCommercial 4.0 International), as described at http://creativecommons.org/licenses/by-nc/4.0/.
Email Alerting Receive free email alerts when new articles cite this article - sign up in the box at the Service top right corner of the article or click here.

\section{|||||||| Providing Precise Solutions for your research.}

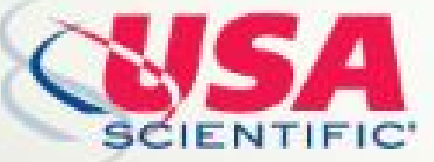

To subscribe to $R N A$ go to:

http://rnajournal.cshlp.org/subscriptions 